\title{
AS POLÍTICAS PÚBLICAS PARA EDUCAÇÃO INFANTIL EM UM MUNICÍPIO DO SUDESTE GOIANO: ANÁLISE DO DESENVOLVIMENTO E DA APRENDIZAGEM
}

\author{
PUBLIC POLICIES FOR EARLY CHILDHOOD EDUCATION \\ IN A MUNICIPALITY IN SOUTHEASTERN GOIÁS: \\ ANALYSIS OF DEVELOPMENT AND LEARNING
POLÍTICAS PÚBLICAS PARA LA EDUCACIÓN DE LA PRIMERA ANÁLISIS DE DESARROLLO Y APRENDIZAJE \\ INFANCIA EN UN MUNICIPIO DEL SURESTE DE GOIÁS:
}

\begin{abstract}
ELAINe LARA Ferreira ${ }^{\mathrm{I}}$ Janaina CaSSIANo Silva ${ }^{\text {II }}$ 'Universidade Federal de Catalão (UFCAT), Catalão/GO - Brasil "Universidade Federal de Catalão (UFCAT), Catalão/GO - Brasil
\end{abstract}

RESUmo Acreditamos na concepção de educação infantil promotora do desenvolvimento e da aprendizagem infantil integral. Uma educação que compreenda a criança de 0 a 6 anos de idade contemplando aspectos históricos e sociais, no processo histórico e dialético. Ademais, ressaltamos o ensino de qualidade, crítico, intencional, rompendo assim com o modelo assistencialista. Nesse sentido, o objetivo geral deste estudo foi identificar e analisar as concepções de desenvolvimento e aprendizagem presentes na Proposta Pedagógica de um município do sudeste goiano para a Educação Infantil à luz da Teoria Histórico-Cultural. Foram objeto de estudo três documentos obtidos junto à Secretária Municipal de Educação. Os dados coletados foram analisados utilizando os núcleos de significação à luz da Teoria Histórico-Cultural. Os resultados possibilitaram afirmar que a concepção de desenvolvimento e aprendizagem ainda está pautada em um modelo estigmatizado, linear e adaptativo do sujeito. As políticas públicas do município são norteadas pelos documentos oficiais, os quais necessitam ainda de uma compreensão integral, que potencialize a Educação Infantil no processo de formação da criança.

Palavras-chave: Educação infantil; Políticas públicas; Teoria histórico-CultuRAL; DESENVOLVIMENTO E APRENDIZAGEM INFANTIL. 
ABSTRaCr We believe in the conception of early childhood education that promotes development and integral child learning. An education that comprehends the child from 0 to 6 years old, contemplating historical and social aspects, in the historical and dialectical process. In addition, we emphasize quality education, critical, intentional, thus breaking with the care model. In this sense, the general objective of this study was to identify and analyze the conceptions of development and learning present in the Pedagogical Proposal of a municipality in the southeast of Goiás for Early Childhood Education in the light of the Cultural-Historical Theory. Three documents were obtained from the Municipal Secretary of Education. The collected data were analyzed using the meaning cores in the light of the Cultural-Historical Theory. The results made it possible to affirm that the conception of development and learning is still guided by a stigmatized, linear and adaptive model of the subject. The public policies of the municipality are guided by official documents, which still need a comprehensive understanding, which potentiates Early Childhood Education in the child's education process.

Keywords: Early Childhood education; Public Policy; Cultural-historical TheORY; Child DEVElopment AND LEARning.

RESUMEN Creemos en la concepción de la educación de la primera infancia que promueve el desarrollo y el aprendizaje integral del niño. Una educación que comprende al niño de 0 a 6 años, contemplando aspectos históricos y sociales, en el proceso histórico y dialéctico. Además, enfatizamos una educación de calidad, crítica, intencional, rompiendo así con el modelo de atención. En este sentido, el objetivo general de este estudio fue identificar y analizar las concepciones de desarrollo y aprendizaje presentes en la Propuesta Pedagógica de un municipio en el sureste de Goiás para la Educación de la Primera Infancia a la luz de la Teoría Histórico-Cultural. Se obtuvieron tres documentos de la Secretaría Municipal de Educación. Los datos recopilados se analizaron utilizando los núcleos de significado a la luz de la teoría histórico-cultural. Los resultados permitieron afirmar que la concepción del desarrollo y el aprendizaje sigue guiada por un modelo estigmatizado, lineal y adaptativo de la asignatura. Las políticas públicas de la municipalidad están guiadas por documentos oficiales, que aún necesitan una comprensión integral, lo que potencia la Educación de la Primera Infancia en el proceso educativo del niño.

Palabras Clave: Educación de la primera infância; Políticas públicas; Teoría hisTÓRICO-CULTURAL; DESARROLlO Y APRENDIZAJE INFANTIL.

\section{INTRODUÇÃo}

O estudo da educação infantil, das práticas educativas, da formação docente e do desenvolvimento infantil, bem como, das políticas públicas para a educação infantil é de extrema importância para o meio acadêmico, a fim de pensarmos uma educação infantil que realmente promova o desenvolvimento integral da criança. Nesse sentido, as concepções de criança, desenvolvimento e educação têm sido objeto de discussões no interior de diferentes correntes teóricas.

De acordo com Davidov (1988), para a escola soviética (VIGOTSKI, LEONTIEV, LURIA, BLONSKI etc.) a tese fundamental é a de que o desenvolvimento psíquico da 
criança desde o começo está mediatizado por sua educação/ensino. O desenvolvimento psíquico das crianças acontece no processo de educação e ensino realizado pelos adultos que organizam a vida da criança, criando condições determinadas para o seu desenvolvimento e transmitindo para ela a experiência social acumulada pela humanidade no período precedente de sua história. Ou seja, os adultos são os portadores dessa experiência social.

Segundo Elkonin (1969), por intermédio dos adultos a criança assimila um amplo círculo de conhecimentos adquiridos pelas gerações precedentes, aprende as habilidades elaboradas socialmente e as formas de conduta que se têm criado na sociedade. Ademais, à medida que as crianças adquirem experiência social se formam nelas distintas capacidades.

Vigotskii (2006) considera que a aprendizagem não é em si desenvolvimento, porém, uma correta organização da aprendizagem da criança conduzirá ao desenvolvimento mental, ativará todo um grupo de processos de desenvolvimento, sendo que essa ativação não poderia produzir-se sem a aprendizagem. Por isso, “[...] a aprendizagem é um momento intrinsecamente necessário e universal para que se desenvolvam na criança essas características humanas não-naturais, mas formadas historicamente" (VIGOTSKII, 2006, p. 115).

Tomando como base este referencial teórico, a Teoria Histórico-Cultural, é que propomos o presente trabalho. Nosso intento foi verificar como se dá na educação infantil, no âmbito das políticas públicas, especificamente do projeto político pedagógico de um município do sudeste goiano e de algumas instituições de educação infantil, a concepção de desenvolvimento e aprendizagem na promoção do desenvolvimento integral da criança de 0 a 05 anos e 11 meses de idade.

Visando contextualizar nossa temática de estudo, realizamos um levantamento bibliográfico do período de 2013 a 2018, na Scientific Electronic Library Online (SCIELO) e no Banco Digital de Teses e Dissertações (BDTD), utilizando os seguintes descritores: Educação Infantil, Teoria Histórico-Cultural, Documentos Oficiais e Políticas Públicas. Esse levantamento nos auxiliou na compreensão de como nosso objeto de estudo se localizava no cenário nacional. Em um primeiro levantamento, localizamos 46 artigos no SCIELO e 284 trabalhos no BDTD, sendo 201 dissertações e 83 teses. Posteriormente, realizamos uma leitura mais detalhada considerando os títulos, temática, pressuposto teórico e metodológico da Teoria Histórico-Cultural. Os resultados são apresentados na tabela a seguir.

Tabela 1: Número de trabalhos selecionados no SCIELO e BDTD (2013-2018).

\begin{tabular}{|c|c|c|c|}
\hline \multicolumn{4}{|c|}{$\begin{array}{l}\text { SCIELO (Artigos) } \\
\text { BDTD (Teses e Dissertações) }\end{array}$} \\
\hline ANO & ARTIGOS & DISSERTAÇÕES & TESES \\
\hline 2013 & 0 & 2 & 1 \\
\hline 2014 & 1 & 4 & 2 \\
\hline 2015 & 3 & 5 & 0 \\
\hline 2016 & 2 & 4 & 3 \\
\hline 2017 & 0 & 1 & 0 \\
\hline 2018 & 0 & 3 & 0 \\
\hline Total & 6 & 19 & 6 \\
\hline
\end{tabular}

Fonte: Elaborado pelas autoras. 
Localizamos seis artigos e 25 trabalhos acadêmicos (19 dissertações e 6 teses) acerca de nossa temática de estudo. Assim, percebemos um baixo número de trabalhos, principalmente referente à perspectiva da Teoria Histórico-Cultural. Ao realizarmos a leitura dos resumos dos trabalhos, notamos que a temática Políticas Públicas na Educação Infantil englobava outras áreas afins, além da Psicologia, como: Geografia, Educação Física, Matemática e Gestões de Comunicação.

$\mathrm{Na}$ perspectiva Histórico-Cultural, tivemos assuntos relacionados com: a formação continuada de professores da Educação Infantil; o processo da passagem Educação Infantil ao Ensino Fundamental; a preocupação na questão de aprendizagem, desenvolvimento infantil e alfabetização das crianças em idade pré-escolar e nas creches; como os profissionais lidam com o bebê; a formação a partir do brincar; as contribuições para o desenvolvimento infantil.

Considerando o exposto, neste estudo apresentamos o trabalho desenvolvido ao longo do ano de 2019 no Programa de Iniciação Científica que teve como objetivo geral identificar e analisar as concepções de desenvolvimento e aprendizagem exibidos na Proposta Pedagógica de um município do sudeste goiano para a Educação Infantil à luz da Teoria Histórico-Cultural. Assim, subdividimos este artigo em sete partes. Inicialmente, apresentamos os referenciais teóricos que embasam nosso estudo, quer sejam, o desenvolvimento e a aprendizagem na primeira infância, e posteriormente as políticas públicas para a educação infantil. Em um terceiro momento trazemos os procedimentos metodológicos. Em seguida, expomos os resultados discussões e os dois núcleos de significação. Por fim, fazemos as considerações finais acerca da realização do estudo.

\section{DESENVOLVIMENTO E APRENDIZAGEM NA PRIMEIRA INFÂNCIA}

Compreender sobre como tem se apresentado a educação infantil no âmbito das políticas públicas, a concepção de desenvolvimento e aprendizagem na promoção do desenvolvimento integral da criança pequena é primordial para uma visão integral da criança e seu processo de desenvolvimento. Inicialmente, Vygotsky (2005, p. 32) afirma que “[...] toda aprendizagem da criança na escola tem uma pré-história". Ou seja, a aprendizagem da criança começa antes da aprendizagem escolar, isto é, a criança ao adentrar na escola já tem uma aprendizagem anterior, que é diferente da aprendizagem que se insere durante o processo de ensino na escola.

A aprendizagem deve ser coesa com o nível de desenvolvimento da criança. As mudanças decorrentes da idade no desenvolvimento psíquico e nas características da personalidade da criança se produzem em momentos diferentes, de acordo com sua vida, suas ações, atividades e condições de educação.

A criança em suas inter-relações com outras crianças ou pessoas que a rodeiam se apropria de elementos dessa interação. Todavia, a aprendizagem é o elemento fundamental para a área de desenvolvimento potencial da criança (VYGOTSKY, 2005). A aprendizagem estimula na criança um grupo de processos internos de desenvolvimento das inter-relações com outros, que em contínuo processo são apropriadas no interior do desenvolvimento, 
transformando em aquisições internas da criança. Portanto, temos de acordo com Manica (2018) que o desenvolvimento infantil se confirma em movimento contínuo dos processos naturais e culturais, nas contradições geradas entre si.

Isto se dá durante toda a vida da criança, em seu processo de constituição pela sociedade, nas diversas formas de conduzir o sistema de conexões, entre as contradições, as satisfações etc. Kostiuk (2005) destaca esse ponto como pertinente para a Psicologia do desenvolvimento da criança, por sua preocupação em manter a relação recíproca entre aprendizagem, educação e desenvolvimento psicointelectual.

Entretanto, deve-se levar em consideração que o desenvolvimento não é um processo simples, pois depende da capacidade e habilidade de cada criança, dos diferentes modos e diversos aspectos do processo de desenvolvimento, da existência de "[...] desenvolvimento do conhecimento, da atividade cognoscitiva, desenvolvimento das qualidades mentais (simples e compostas, particulares e gerais) que entram neste processo, e das propriedades funcionais do cérebro que subexistem nelas" (KOSTIUK, 2005, p. 48). Acerca disso, a criança adquire nova capacidade de desenvolvimento em uma das funções progressivamente, à medida que provoca mudanças em suas ações, significações e símbolos.

Bogoyavlensky e Menchinskaya (2005, p. 71) complementam que "[...] em cada nível de idade pode-se observar a coexistência de etapas diferentes. Há, contudo, indícios de uma precedente etapa de desenvolvimento, mas também surgem novos fenômenos que podem ser bastante típicos e desenvolver-se no período seguinte". Para compreender em qual nível a criança se encontra, é preciso observar os fatores biológicos e sociais, por exemplo, a criança em determinada idade pode ter limitações em atividades cognoscitivas, mas, no entanto, pode desenvolver experiências sociais. Entretanto, não podemos nos esquecer de que para ter o desenvolvimento psíquico é necessário criar capacidades potenciais na criança.

Diante disso, é preciso que saibamos distinguir o desenvolvimento mental da aquisição de conhecimento, já que não são determinantes em si. "O processo de aprendizagem muda não só o que se pensa conscientemente, mas também os modos como se produz esta reflexão, ou seja, o processo mental implicado" (BOGOYAVLENSKY; MENCHINSKAYA, 2005, p. 72).

Saviani (2012, p. 60) destaca que a educação é a manifestação da ação social do homem, ou seja, "[...] voltada para a formação da personalidade humana em seus múltiplos aspectos. É um fenômeno social historicamente determinado, compreendendo relações sociais e formas de comportamento social". Arce (2013a, p. 23) acrescenta que "[...] a interação com os adultos é, portanto, responsável pelo desenvolvimento bio-psico-social desta criança; pois é através das mediações que esta interação propicia que a criança irá se construir e se colocar no mundo".

Desse modo, como aponta Barbosa (2013, p. 117), a educação infantil assegura à criança, o direito de desenvolvimento, "[...] por meio de processos intencionais e planejados de ensino, a relação com a cultura". Esse tipo de relação, entre a criança-educador, ou criança/objeto, faz que se tenha uma posição ativa nas relações tanto de conhecimento, como pedagógica. Significa que "[...] a relação entre o ensino e o desenvolvimento das funções psíquicas da criança, passa necessariamente pelas aprendizagens que se realizam" (BARBOSA, 2013, p. 119). 
Por meio de estímulos, no processo de desenvolvimento interno a criança ativa em determinado grupo de inter-relações com os outros, em contínuo desenvolvimento, pode fazer que se adquiram novas aquisições, tornando-as internas à criança. "A diferença entre o nível das tarefas realizáveis com o auxílio dos adultos e o nível das tarefas que podem desenvolver-se com uma atividade independente define a área de desenvolvimento potencial da criança" (VYGOTSKY, 2005, p. 36).

Ou seja, é necessário pensar a educação por meio da possibilidade de criação do desenvolvimento, fundamentado no processo de interiorização que vai do plano interpsicológico para o intrapsicológico. A criança no processo de ensino, ao realizar atividades, busca solucionar problemas no decurso da aprendizagem, e isso promove o desenvolvimento da mesma, que converte do nível real (intrapsíquico) ao nível potencial (interpessoal): zona de desenvolvimento iminente. Assim, pensar os processos educativos, nessa conceituação, é afirmar que tais "[...] processos se concretizam pelas relações estabelecidas entre indivíduos reais e concretos em uma determinada sociedade" (BARBOSA, 2012, p. 126).

Dessa forma, compreendemos que, para que se tenha um ambiente educacional de qualidade na promoção do desenvolvimento da criança, é necessário que o educador conheça a criança em seu contexto sócio, histórico e cultural. Ademais, que conheça os conceitos que ela traz, em qual fase do desenvolvimento se encontra, construindo uma educação infantil com possibilidades de constituição da criança, auxiliando a desenvolver e inserir nas relações e no mundo. "O ensino na educação infantil é o momento em que o professor leva a criança a formar conceitos, a confrontar conhecimentos. Transmite a esta criança todo o conhecimento acumulado pela humanidade e presente nos objetos que nos cercam" (ARCE, 2013b, p. 36). O ensino deve ser planejado pelo professor que ao pensar em conjunto com a criança, introduz novos conhecimentos, explora o mundo, na interação do ensinar com a criança.

Feito esta breve ponderação acerca do desenvolvimento e aprendizagem para a Teoria Histórico-Cultural, a seguir trazemos algumas discussões pertinentes no campo das políticas públicas para a Educação Infantil.

\section{As POLÍticas públicas PaRa a EduCAÇÃo InFANTIL}

A educação infantil por muito tempo no Brasil foi tratada como meramente questão de assistência social, referindo-se às creches e pré-escolas como um lugar de cuidado e atividades lúdicas, com cunho não pedagógico. Entretanto, com a Lei de Diretrizes e Bases da Educação Nacional (LDB), lei n. 9.394/96 (BRASIL, 1996) que se iniciou após a promulgação da Constituição de 1988 e finalizou em dezembro de 1996, avançou-se na estruturação da educação nacional em dois níveis, a educação básica e a educação superior. Nesse sentido, a educação infantil passou a ser vista como direito da criança, dever do Estado, e a primeira etapa da educação básica, seguida do ensino fundamental e do ensino médio (BRASIL, 1996).

Nessa perspectiva, estipulou-se que nessa etapa a educação infantil se desenvolvesse em: "[...] I- creches, ou entidades equivalentes, para crianças de até 3 anos de idade; II- 
pré-escolas, para crianças de 4 a 6 anos de idade" (SAVIANI, 2012, p. 68). Nesse sentido, será ofertado o atendimento gratuito em creches e pré-escolas, no qual, o Estado tem como principal papel efetivo garantir ofertas de vagas e condições favoráveis para a realização da educação e desenvolvimento da criança dessa faixa etária.

Após a LDB de 1996, em 1998 a COEDI/MEC publicou o Referencial Curricular para a Educação Infantil (RCNEI) (BRASIL, 1998). O Referencial passou a vigorar no ano de 1998 e teve como principal objetivo realizar um trabalho conjunto entre os educadores de creches, pré-escolas e as crianças, na possibilidade de integralização do educar e cuidar. Ou seja, esse documento atuaria na promoção da formação das crianças, contribuindo para socialização e o aprendizado de conhecimentos, a partir da realidade social e cultural. A concepção de infância nos documentos oficiais do MEC, desenvolvido no RCNEI tem como objetivo "[...] servir como um guia de reflexão sobre objetivos, conteúdos e orientações didáticas para os profissionais que atuam diretamente com crianças de 0 a 6 anos" (SILVA, 2012, p. 85).

O RCNEI é dividido em três volumes que incluem concepções de criança, educação, instituição e o perfil de professores na educação infantil. Também são trabalhados no documento a questão da faixa etária, do conteúdo a ser trabalhado em sala, da seleção de materiais, da avaliação do docente na prática educativa, além da importância do acolhimento familiar. Esse documento define que a educação infantil deve se pautar nos âmbitos de experiência Formação Pessoal e Social (BRASIL, 1998).

O RCNEI considera, ainda, que a criança saudável desenvolve e aprende a partir de sua integralidade, seja biológico, psíquico, emocional, cognitivo, social, em determinada cultura e período histórico (BRASIL, 1998). Nesse contexto, passam a ser pautas as políticas públicas para a Educação Infantil e o conceito de creches começa a tem um novo escopo, compreendido como atendimento à criança, e não um segmento social discriminatório, assistencialista. O documento traz ainda as crianças como sujeitos históricos e de direitos, seja nas interações, relações e nas práticas que constroem sua identidade pessoal e coletiva, prioritariamente na construção de políticas públicas (BRASIL, 1998).

No ano 2006, foram publicados pelo MEC os Parâmetros de Qualidade para a Educação Infantil. Oo documento tem por objetivo “[...] estabelecer padrões de referência orientadores para o sistema educacional no que tange a organização e ao funcionamento das instituições de educação infantil" (SILVA, 2012 p. 87). Esse documento é composto por dois volumes, abarcando desde a concepção da criança, a trajetória histórica da educação infantil, pesquisas sobre a área, caracterização do sistema educacional nas instituições etc. (BRASIL, 2006).

O documento considera que, "[...] a criança é um sujeito social e histórico que está inserido em uma sociedade na qual partilha uma determinada cultura. É profundamente marcada pelo meio social em que se desenvolve, mas também contribui para ele" (SILVA, 2012, p. 87). A criança se insere na cultura e por ela é transformada, sendo produtora da história. No documento se trata ainda da interação social entre a criança, o adulto ou outras crianças na promoção de desenvolvimento e aprendizagem. Nesse contexto, o documento retrata o cuidar e educar tendo como principal ponto auxiliar as crianças em suas atividades, as quais não conseguem realizar sozinhas, no cuidado em sua totalidade, seja na dimensão física, psíquica, emocional, social. 
Em 2006, temos também o documento Política Nacional de Educação Infantil que se refere ao "[...] direito das crianças de zero a seis anos a educação, tem por finalidade fornecer subsídios para um processo democrático de implementação das políticas públicas para as crianças de 0 a 6 anos" (SILVA, 2012, p. 88). Composto por um volume, esse documento aborda as diretrizes da política nacional de educação infantil, caminhos, objetivos, estratégias etc. Além disso, no documento considera-se a criança como um ser capaz de criação, constituindo-se em diferentes relações, ou seja, sujeito histórico, social e cultural.

Nesse documento ainda se afirma que "[...] na educação de crianças de 0 a 3 anos predominam os cuidados com a saúde, a higiene e a alimentação, enquanto a educação das crianças de 4 a 6 anos tem sido concebida e tratada como antecipadora/preparatória para o ensino fundamental" (SILVA, 2012, p. 91). Com relação a esse documento, Silva (2012) evidencia que se faz necessário que todos os envolvidos no processo pedagógico, crianças, professoras, pais, comunidade e profissionais de áreas afins, estejam engajados na promoção do saber produzido no cotidiano destes.

Outro marco importante nessas discussões referentes à educação infantil é a Emenda Constitucional n. 059/2009 (INSUMOS, 2010), que torna obrigatória a educação para a faixa etária dos 04 aos 17 anos. Porém, vale ressaltar, conforme afirma Campos (2010, p. 11), que essa emenda "[...] foi aprovada sem que fosse precedida por maiores discussões na sociedade, nos meios especializados e no próprio Congresso Nacional". A autora ainda alerta que um dos efeitos das medidas estabelecidas por essa emenda no Brasil "[...] é a tendência de crianças cada vez mais jovens serem empurradas para as etapas seguintes da educação, sem que as escolas e as práticas educativas sejam antes adaptadas para as especificidades de sua faixa etária" (CAMPOS, 2010, p. 11).

Notamos que historicamente a luta pela educação infantil é continua, seja nos fóruns estaduais, em redes de creches e no Movimento Interfóruns de Educação Infantil do Brasil (MIEIB), ${ }^{1}$ organização para prosseguir coletivamente questões centrais da política de educação infantil (KRAMER, 2006). Mediante todo o aparato legislativo, tecnológico e científico em relação à educação infantil como direito da criança, muitos foram os avanços, entretanto, inversamente muitos retrocessos também acompanham historicamente a maioria das escolas infantis, visto que ainda existe uma divergência entre o que foi regulamentado e a realidade institucional (PASCHOAL; MACHADO, 2009). É necessário observarmos que ainda falta a democratização e universalização da Educação Infantil no Brasil, com relação aos níveis de acesso, qualidade, profissionais da educação e valorização da formação continuada dos professores da educação infantil.

Diante disso, ao analisar as políticas públicas, o intuito é a compreensão do processo de elaboração e execução dos projetos, programas e planos de diversos setores, a fim de avaliar a relação estabelecida com os processos políticos e várias questões científicas existentes, no caso específico, a educação infantil (RODRIGUES, 2013).

\footnotetext{
"A história do MIEB, enquanto movimento social de luta em prol de uma educação infantil pública, laica e de qualidade se inicia em 1999, a partir da articulação de alguns comitês estaduais que já discutiam a demanda por educação infantil no país e desde então vem pautando suas ações de incidência política nos temas de maior relevância no cenário nacional, garantindo a consideração das especificidades locais a partir da intervenção dos fóruns estaduais" (MIEIB, 2020, s/p).
} 
Nesse sentido, no próximo item apresentamos nossos procedimentos metodológicos para a construção deste trabalho.

\section{Procedimentos metodológicos}

A metodologia deste artigo pauta-se nos fundamentos metodológicos e filosóficos do materialismo histórico-dialético, tendo como base os referenciais teóricos da Teoria Histórico-Cultural. Marx (1983, p. 20) destaca que "[...] a pesquisa tem que captar detalhadamente a matéria, analisar as suas várias formas de evolução e rastrear sua conexão íntima. Só depois de concluído esse trabalho é que se pode expor adequadamente o movimento real".

Foram objetos de estudo a Proposta Pedagógica de um município do sudeste goiano para a Educação Infantil, bem como, os demais documentos municipais referentes à educação infantil publicados nos últimos dez anos. Escolhemos esse material por intermédio da Secretaria Municipal de Educação. Após a localização do material existente no município, foi desenvolvida uma primeira leitura do mesmo com o intuito de identificar as ideias presentes nesses documentos. Destacamos que os dados contidos nos documentos foram analisados utilizando-se os núcleos de significação, de acordo com Aguiar e Ozella (2013). O referencial teórico da pesquisa pautou-se na Teoria Histórico-Cultural.

Para a realização da identificação do material documental existente no município, entramos em contato primeiramente com a coordenadora da Educação Infantil, na Secretaria Municipal de Educação, fizemos os devidos esclarecimentos com relação à pesquisa, aos instrumentos de análise dos dados e deixamos uma cópia do projeto de pesquisa na Secretaria Municipal de Educação. Esse contato inicial teve como finalidade identificar os documentos existentes no município.

De acordo com a Coordenadora, no município ainda está em construção a proposta pedagógica para a educação infantil, que tem previsão para a conclusão no ano de 2020. Obtivemos três documentos junto à Secretaria Municipal de Educação: 1) o Ementário Educação Infantil (2002), 2) Plano Municipal de Educação (2011) e 3) a Proposta Pedagógica Global da Rede Municipal de Ensino (Educação Infantil - Ensino Fundamental, 2013). A seguir, apresentamos os resultados do estudo.

\section{Resultados E Discussões}

Em relação à temática abordada nesses documentos analisados, o Ementário Educação Infantil (2002), trata-se de um guia educacional sobre conteúdos, tem temáticas específicas, complementado com objetivos e orientações didáticas, para os profissionais que atuam com crianças de zero a 6 anos de idade. O segundo, Plano Municipal de Educação (2011), foi composto por um histórico da cidade, abrangendo a educação infantil, fundamental, de Jovens e Adultos, a distância, profissional, especial, do campo e a educação superior, com objetivos e metas, diagnósticos e diretrizes que norteiam os profissionais educacionais. $\mathrm{O}$ documento abarcou ainda acerca do financiamento e gestão, formação e valorização dos 
profissionais da Educação e acompanhamento e avaliação, no qual representam a Educação no Município de Catalão. No terceiro documento, a Proposta Pedagógica Global da Rede Municipal de Ensino (Educação Infantil - Ensino Fundamental, 2013), temos referências a respeito do panorama do ensino fundamental e infantil no Brasil e no município; a Proposta Curricular e; ainda traz a concepção de infância na Rede Municipal de Educação, a legislação, o planejamento e desenvolvimento de projetos na Educação Infantil e sobre o professor, seu perfil e formação.

No decorrer da análise percebemos que o Ementário Educação Infantil (2002) estava contemplado na Proposta Pedagógica Global da Rede Municipal de Ensino (Educação Infantil - Ensino Fundamental, 2013), diante disso, a análise documental foi realizada com base no Plano Municipal de Educação (2011) e na Proposta Pedagógica Global da Rede Municipal de Ensino (Educação Infantil - Ensino Fundamental, 2013).

Vale destacar que buscamos analisar os documentos por meio de núcleos de significação que permitem a apreensão dos sentidos não só a relação sujeito/objeto, contudo, a própria constituição do sujeito, a qual produz um conhecimento que se aproxime do concreto, de múltiplas determinações, cuja forma de apresentação é por meio dos significados. Portanto, trata-se de um processo construtivo de não contentar somente com a descrição dos fatos, mas investigar o processo de constituição do objeto pesquisado, isto é, pesquisar em seu processo histórico (AGUIAR; OZELLA, 2013).

Desse modo, é essencial a historicidade, a concepção de homem. Um homem constituído na relação dialética com o social e a sua história assim, é ao mesmo tempo, único, singular e histórico. O homem produz e revela sua forma humana de existência, expressa, a maneira como produz, a historicidade social, a ideologia, relações sociais, constituído na e pela atividade. Também é constituída sua identidade, o seu modo singular, o novo que pode produzir significados e sentidos em seu processo social e subjetivo. A análise com base nos núcleos de significação tem o uso de categorias durante todo o processo de interpretação e inferência sobre o sujeito/objeto, sendo estas: mediação, historicidade, necessidade e motivos (AGUIAR; OZELLA, 2006).

Diante disso, tal procedimento é composto por etapas de construção dos núcleos de significação, sendo estes: levantamento de pré-indicadores, sistematização de indicadores e construção dos Núcleos de Significação e análise dos Núcleos de Significação (intra e internúcleos). São os movimentos que permeiam o processo construtivo-interpretativo realizado pelo pesquisador.

A primeira etapa é o levantamento de pré-indicadores que consistem na identificação de palavras com significado, dão indícios do modo de pensar, sentir e agir do sujeito em questão. Palavras cujos significados expressam a materialidade histórica do sujeito, da realidade à qual está inserida. Entretanto, ressaltamos que não se refere à palavras isoladas. De acordo com Aguiar e Ozella (2013, p. 309), os pré-indicadores, são "[...] trechos de fala compostos por palavras articuladas que compõem um significado". É o ponto inicial do pesquisador, os pré-indicadores investigam o sujeito empírico.

A segunda etapa é o processo de articulação dos pré-indicadores, de aglutinação, seja pela similaridade, complementaridade ou pela contraposição (AGUIAR; OZELLA, 2013), que resultará na sistematização de indicadores diante da realidade pesquisada. 
A terceira etapa consiste na construção dos Núcleos de Significação, na qual se articulam e sintetizam os possíveis conteúdos resultantes do processo de análise desde o levantamento dos pré-indicadores. Contudo, se distancia do empírico e se aproxima da realidade concreta, dos sentidos constituídos do sujeito com relação à realidade na qual está inserido. Nos Núcleos de Significação, é preciso compreender os conteúdos por meio da particularidade do sujeito/objeto de pesquisa, e buscar entender as relações estabelecidas com outras pessoas e eventos (AGUIAR; OZELLA, 2013). Assim, o processo de construção dos núcleos de significação é construtivo-interpretativo, pois permeia a compreensão crítica do pesquisador com relação à realidade.

A análise se inicia de um processo intranúcleo para uma articulação internúcleos, realizando um movimento de interpretação pelo pesquisador, na elaboração de sínteses complexas. Nesse contexto, fazemos uma reflexão sobre o referencial teórico adotado, retomamos o objetivo de pesquisa e destacamos os resultados obtidos.

Dessa forma, apresentamos nos quadros seguintes o passo a passo para a construção dos núcleos de significação a partir dos dados obtidos nos documentos selecionados:

Quadro 1: Organização dos Pré-indicadores e Indicadores.

\begin{tabular}{|c|c|}
\hline Pré-indicadores & Indicadores \\
\hline 1) Desenvolvimento integral; & \multirow{2}{*}{$\begin{array}{l}\text { 1) A atuação pedagógica no processo } \\
\text { de desenvolvimento e aprendizagem da } \\
\text { criança na faixa etária de zero a } 5 \text { anos } \\
\text { de idades; }\end{array}$} \\
\hline 2) Ampliação das experiências e dos conhecimentos; & \\
\hline 3) A criança é um sujeito social e histórico; & \multirow{2}{*}{$\begin{array}{l}\text { 2) A mediação do meio social na } \\
\text { constituição da identidade da criança e } \\
\text { as relações entre adultos e crianças no } \\
\text { contexto escolar; }\end{array}$} \\
\hline $\begin{array}{l}\text { 4) A Educação Infantil inclui duas funções a essa } \\
\text { faixa etária: Cuidar e Educar; }\end{array}$ & \\
\hline $\begin{array}{l}\text { 5) O professor de Educação Infantil compreende } \\
\text { os processos psíquicos infantis, que abarcam todo } \\
\text { o desenvolvimento físico, afetivo, emocional, } \\
\text { psicomotor e cognitivo; }\end{array}$ & \multirow{2}{*}{$\begin{array}{l}\text { 3) Ampliação dos saberes docentes a } \\
\text { uma concepção pedagógica no processo } \\
\text { de ensino e aprendizagem;) }\end{array}$} \\
\hline $\begin{array}{l}\text { 6) Atitude do profissional, compete propor às crianças } \\
\text { desafios, situações - problemas, sendo um desafiador } \\
\text { e apoiador das aprendizagens infantis; }\end{array}$ & \\
\hline $\begin{array}{l}\text { 7) Eixos norteadores adotados na Rede Municipal } \\
\text { de Ensino, desenvolvidos pelos profissionais em } \\
\text { Educação Infantil: Linguagens, Cultura, Percepção, } \\
\text { Interação, Afetividade e Ludicidade; }\end{array}$ & \multirow{2}{*}{$\begin{array}{l}\text { 4) A construção de recursos, a Proposta } \\
\text { Curricular do Município e a formação } \\
\text { continuada dos professores como } \\
\text { processo de melhoria e reflexão sobre a } \\
\text { prática pedagógica. }\end{array}$} \\
\hline 8) Formação continuada para os docentes. & \\
\hline
\end{tabular}

Fonte: Elaborado pelas autoras. 
No Quadro 1 elencamos os pré-indicadores e indicadores que conseguimos apreender após leitura e análise do nosso material, ou seja, os documentos selecionados. Organizamos oito (08) pré-indicadores e, a partir desses quatro (04) indicadores.

No Quadro 2 trazemos os nossos dois Núcleos de Significação, construídos a partir dos nossos pré-indicadores.

Quadro 2: Organização dos Indicadores e Núcleos de Significação.

\begin{tabular}{|c|c|}
\hline Indicadores & Núcleos de Significação \\
\hline $\begin{array}{l}\text { 1) A atuação pedagógica no processo de } \\
\text { desenvolvimento e aprendizagem da criança na faixa } \\
\text { etária de zero a cinco anos de idades; }\end{array}$ & \multirow{2}{*}{$\begin{array}{l}\text { 1) A construção pedagógica no processo } \\
\text { de desenvolvimento e aprendizagem da } \\
\text { criança enquanto sujeito sócio-histórico; }\end{array}$} \\
\hline $\begin{array}{l}\text { 2) A mediação do meio social na constituição da } \\
\text { identidade da criança e as relações entre adultos e } \\
\text { crianças no contexto escolar; }\end{array}$ & \\
\hline $\begin{array}{l}\text { 3) Ampliação dos saberes docentes a uma concepção } \\
\text { pedagógica no processo de ensino e aprendizagem; }\end{array}$ & \multirow[b]{2}{*}{$\begin{array}{l}\text { 2) A prática docente e o processo de } \\
\text { formação continuada dos profissionais } \\
\text { no âmbito da Educação Infantil. }\end{array}$} \\
\hline $\begin{array}{l}\text { 4) A construção de recursos, a Proposta Curricular do } \\
\text { Município e a formação continuada como processo } \\
\text { de melhoria e reflexão sobre a sua prática pedagógica. }\end{array}$ & \\
\hline
\end{tabular}

Fonte: Elaborado pelas autoras.

A seguir, trazemos as análises com base nesses dois núcleos em articulação com o nosso referencial teórico, a Teoria Histórico-Cultural.

A construção pedagógica no processo de desenvolvimento e aprendizagem da criança enquanto sujeito sócio-histórico

Barbosa (2013) afirma que, a criança não nasce com aptidões inatas, a construção dependerá das condições concretas de vida e educação, o acesso que a criança tem à sociedade na qual está inserida e a escola que frequenta, a cultura, e o meio social. Nessa concepção, a educação infantil tem um papel fundamental no processo de humanização da criança, com possibilidades de inserir e criar níveis de aquisição do meio social, cultural, fazendo que tenha acesso e permita se reconhecerem como gênero humano.

Apreende-se da escrita dos documentos, o Ementário Educação Infantil (2002), o Plano Municipal de Educação (2011) e a Proposta Pedagógica Global da Rede Municipal de Ensino (Educação Infantil - Ensino Fundamental, 2013) que esses aspectos essenciais para o cumprimento de uma Educação Básica têm como finalidade o desenvolvimento do educando visando assegurar a construção da aprendizagem indispensável na formação e constituição da criança. A LDB, o RCNEI e as Diretrizes Curriculares Nacionais para a Educação Infantil (DCNEI) são os documentos norteadores do nosso material analisado. 
Os documentos municipais concebem a criança em seu desenvolvimento integral até 6 anos de idade, considerando seus aspectos físico, psicológico, intelectual e social. A Proposta Pedagógica Global da Rede Municipal de Ensino (2013, p. 45) entende a criança como "sujeito ativo, inventivo, investigador, afetivo, por meio do adulto/professor constrói e amplia o repertório cultural e conhecimento de mundo".

Observamos que essa concepção é elemento desencadeador do desenvolvimento das crianças e dos conhecimentos que elas vão adquirindo, afirmando ser essa uma experiência pelo processo de transformação da realidade pela convivência em sociedade. Saviani (2012) destaca que a educação se constitui nas diversas relações sociais, nas ações e produção de existência humana, nas necessidades materiais, criando instrumentos, meios para ação e transformação, significados, símbolos, representações, aquisições novas.

No que tange a esse pensamento, fica perceptível nos documentos municipais a implicação em considerar na Educação Infantil a criança como sujeito social e histórico, inserida em uma sociedade, em determinada cultura, a qual é marcada pelo meio social, sendo por essa modificada. Outro ponto em destaque nos documentos do município é a interação como fator fundamental preponderante no desenvolvimento infantil e na construção de conhecimentos entre crianças/crianças ou crianças/adultos.

Também são apresentados nos documentos o cuidar e educar como funções complementares. Ou seja, o cuidado centra-se nas relações afetivas e emocionais estabelecidas entre adultos e crianças, no compartilhamento do mesmo espaço de aprendizagem, e o educar se refere às ações planejadas com objetivos, inseridas na rotina diária que visam à ampliação do repertório cultural das crianças.

O referencial que pauta os documentos municipais está alicerçado na teoria sociointeracionista, que considera a criança enquanto sujeito sócio-histórico, no processo de interações estabelecidas entre a criança e o seu meio físico e social.

Kostiuk (2005) discute tal aspecto sobre educação e ressalta que a formação da criança está no decurso do desenvolvimento à medida que se insere e se apropria de novos conhecimentos, ações e capacidades de satisfazê-la, abrindo possibilidades de maturação no decorrer das atividades da criança, tanto no âmbito da educação, quanto de questões da vida cotidiana. Ou seja, “[...] são pelas inter-relações culturais que se ampliam e se formalizam por meio das atividades educativas que garantimos o acesso das crianças a níveis de desenvolvimento intelectual e social mais elevados" (BARBOSA, 2012, p. 127).

Desse modo, “[...] cada criança pode ressignificar o mundo e o conhecimento, (re) apresentando de um jeito próprio, produzindo novas culturas e formas de se pensar e de ser ver o mundo" (ARCE, 2013a, p. 24). O conhecimento da criança é construído a partir da interação com o meio a qual está inserida e com as outras crianças de forma ativa.

Bogoyavlensky e Menchinskaya (2005) constatam que é preciso levar em consideração, a idade e o desenvolvimento psíquico por um lado, e por outro, a aprendizagem. As mudanças que ocorrem da idade no desenvolvimento psíquico e nas características da personalidade se produzem em momentos diferentes, de acordo com a vida da criança, de suas ações, atividades e condições de educação.

A seguir, trazemos a análise do segundo núcleo de significação. 


\section{A PRÁtica doCENTE E O PROCESSO DE FORMAÇÃo CONTINUADA dOS PRO- FISSIONAIS NO ÂMBITO DA EDUCAÇÃo INFANTIL}

No que se refere à questão da prática docente e do processo de formação continuada dos professores, foi perceptível o estabelecimento de uma reflexão sobre a prática docente cotidiana em termos pedagógicos, éticos e políticos, além da busca de mediação do processo de aprendizagem e o desenvolvimento infantil, considerando o coletivo de crianças em suas singularidades. Kostiuk (2005) salienta que, compreender os métodos educativos contribui para uma melhor prática educativa, tornando-se eficiente quando respalda a educação nas leis e características específicas do processo de desenvolvimento e aprendizagem, sendo capaz de conduzir com êxito uma educação ativa.

A escola é o "[...] espaço capaz de propiciar a apropriação crítica e criativa das múltiplas manifestações culturais, e ao mesmo tempo, é espaço de produção e reprodução da cultura" (SAVIANI, 2012, p. 61). Os documentos do município afirmam a necessidade de o professor assumir um papel primordial no processo da Educação Infantil de ampliação do repertório cultural da criança por meio da elaboração de um trabalho pedagógico. Além disso, o professor deve ser capaz de facilitar a interação social, promover a aprendizagem cooperativa, priorizando um espaço que integralize criança, professores, funcionários da instituição e pais.

O espaço da Educação Infantil conforme a proposta pedagógica do município (2013) é regido por regras, organização, sistematização de tempo e espaço, materiais didáticos - pedagógicos e planejamento. O currículo é integrado englobando tempo, espaço, interações, linguagens e brincadeiras. Esse documento municipal traz ainda que o professor não deve partir de conteúdos isolados entre si, mas integrados pela intencionalidade pedagógica do professor e a criança. Nesse sentido, a criança é ativa, toma iniciativas, decisões, é autônoma, contando com o apoio do docente na instituição, constituído de experiências, construindo assim, significações partilhadas. Destarte, concordamos com Saviani (2012, p. 56) que "[...] o currículo na ação diz respeito não somente a saberes e competências, mas também a representações, valores, papéis, costumes, práticas compartilhadas, relações de poder, modos de participação e gestão, etc.". Assim, Saviani (2012) defende a ideia de diretrizes gerais, elementos básicos, trabalhando de acordo com características e condições específicas. Contudo, são necessárias discussões, com a participação e elaboração conjunta, da equipe escolar no todo, em suas organizações, principalmente os professores, como agentes ativos na formação do ensino escolar.

Na elaboração e realização do currículo devemos atentar para as políticas curriculares nacionais, o que fica evidente no município, uma vez que a política para a Educação Infantil se baseia nas diretrizes nacionais, nas normas complementares estaduais, nas sugestões dos referenciais curriculares nacionais e nas normas do Conselho municipal de Educação.

O currículo é uma seleção possível entre debates, discussões e concepções diversas da equipe escolar. Entretanto, o currículo na ação ocorre entre professor-aluno, na relação pedagógica ativa, nas atividades a serem desenvolvidas, podendo modificar a elaboração da proposta curricular ofertada. A reflexão sobre o conteúdo de ensino está em um processo contínuo no cotidiano escolar dos professores, com a equipe escolar da educação, nos vários níveis envolvidos, de graus e modalidades curriculares (SAVIANI, 2012). 
Além disso, os documentos analisados abarcam ainda a formação continuada dos profissionais da Educação Infantil que tenha a prática como eixo condutor, com objetivo de aprimorar, aperfeiçoar e possibilitar discussões, reflexões, melhoria na construção pedagógica, visando a autoformação, capacitação, atualizações em seu exercício profissional. Discutir modelos e práticas educativas consiste em não partir de metas gerais ou de necessidades particulares da criança, mas, da possibilidade de criar um espaço efetivo de símbolos que auxiliam a criança no processo educativo. A educação deve ser desenvolvida como produto, numa relação mediadora entre criança-adulto, representado no contexto das creches e pré-escolas (BARBOSA, 2012).

O ensino nas escolas não deve se limitar apenas a transmitir ao aluno "[...] determinados conhecimentos, a formar um mínimo de aptidões e de hábitos. A sua tarefa é desenvolver o pensamento dos alunos, a sua capacidade de analisar e generalizar os fenômenos da realidade, de raciocinar corretamente" (KOSTIUK, 2005, p. 50). Por meio de uma programação do ensino se cria a possibilidade de aquisição do desenvolvimento a partir de conhecimentos que devem ser adquiridos para formar os sistemas de conexões temporais.

Desse modo, o professor promove a aprendizagem a partir de recursos pedagógicos, por meio das brincadeiras, diálogo, atividades direcionadas, articulando as capacidades de cada criança, sejam elas, afetivas, emocionais, sociais e cognitivas. Além disso, o professor apresenta em sala de aula, valores, costumes, diversidade étnica e social, bem como as diferenças existentes no cotidiano, proporcionando a socialização e o respeito histórico-social existente na sociedade. Nesse processo, o espaço da escola estabelece meios para que as crianças se constituam enquanto sujeito de direitos e significados (ARCE, 2013a).

A educação compreendida como fenômeno histórico e cultural tem possibilidade de problematizar os desafios da realidade escolar a qual a criança está inserida em seu cotidiano. Assim, o processo de aprendizagem da criança, é construído essencialmente por mediação e não individualmente, ou seja, é uma construção dos processos de conhecimentos, que se dá historicamente (BARBOSA, 2012).

\section{CONSIDERAÇões FINAIS}

Os resultados obtidos nesta pesquisa se referem à concepção de desenvolvimento e aprendizagem presente nas Políticas Públicas municipais de um município do sudeste goiano. Cabe destacarmos que estes se pautam em uma teoria sociointeracionista, um modelo que compreende o desenvolvimento da criança enquanto sujeito ativo no seu processo de ensino-aprendizagem. Ademais, a interação da criança com o contexto favorece a assimilação do saber produzido pelo grupo ao qual ela pertence.

Devemos atentar para pontos essenciais com relação ao processo de ensino-aprendizagem na Educação Infantil. O desenvolvimento e a aprendizagem infantil da criança de 0 a 5 anos e 11 meses de idade são fenômenos históricos e dialéticos e não mecanismos adaptativos do comportamento. Ademais, é necessário entendermos que cada estágio do desenvolvimento não é imutável e sim se vincula à relação principal da criança com a realidade que ela está inserida. 
A ideia de infância e políticas de atendimento à criança evoluiu ao longo dos séculos, conforme os arranjos da sociedade e possibilitou discutir sobre o desenvolvimento e a aprendizagem infantil, considerando a criança enquanto sujeito histórico, em sua integralidade social, psíquica, física e afetiva. Nessa perspectiva, a Educação Infantil tem tido avanços, mas é recente o reconhecimento como dever do Estado e como primeira etapa da Educação Básica. As mudanças não aconteceram somente referentes à nomenclatura, mas no que se refere ao conceito de Educação Infantil, rompendo com o modelo de amparo/ assistencialismo para o direito educacional, ou seja, as crianças que frequentam creches e pré-escolas devem ser consideradas sujeitos de direitos.

Entendemos que é necessário investigar em relação à prática docente e à formação continuada, se os espaços, materiais, currículo e planejamento pedagógicos são adequados, visando uma educação infantil que tenha como foco a intencionalidade do trabalho educativo para a promoção do desenvolvimento integral das crianças. Assim, esperamos que esta pesquisa possa colaborar substancialmente no fomento de uma prática educativa crítica, ética e comprometida com a formação integral da criança.

\section{REFERÊNCIAS}

AGUIAR, W. M. J.; OZELLA, S. Apreensão dos sentidos: aprimorando a proposta dos núcleos de significação. R. bras. Est. Pedag., Brasília, v. 94, n. 236, jan./abr., 2013, p. 299-322.

AGUIAR, W. M. J.; OZELLA, S. Núcleos de Significação como Instrumento para a Apreensão da Constituição dos Sentidos. Psicologia Ciência e Profissão, v. 26, n. 2, 2006, p. 222-245.

ARCE, A. Interações ou Brincadeiras? Afinal o que é mais importante na educação infantil? E o ensino como fica? In: ARCE, A (Org.). Interações e Brincadeira na Educação Infantil. Campinas, SP: Editora Alínea, 2013a. p. 17-40.

ARCE, A. O Referencial Curricular Nacional para a Educação Infantil e o Espontaneísmo: (re)colocando o ensino como eixo norteador do trabalho pedagógico com crianças de 4 a 6 anos. In: Arce, A; MARTINS, L. M (Orgs.). Quem tem medo de ensinar na Educação Infantil?: em defesa do ato de ensinar. Campinas, SP: Editora Alínea, 2013b, p. 13-37.

BARBOSA, E. M. Ensinar ou aprender? uma caracterização das práticas educativas realizadas junto às crianças de 3 anos. In: ARCE, A.; JACOMELI, M. R. M. (Orgs.). Educação infantil versus educação escolar? Entre a (des)escolarização e a precarização do trabalho pedagógico nas salas de aula. Campinas, SP: Autores Associados, 2012, p. 107-128.

BARBOSA, E. M. Interações, Aprendizagens e Desenvolvimento Humano em Contextos Escolares para a Infância. In: ARCE, A. (Org.). Interações e brincadeiras na Educação Infantil. Campinas, SP: Editora Alínea, 2013, p. 113-139. 
BOGOYAVLENSKY, D. N.; MENCHINSKAYA, N. A. Relação entre Aprendizagem e Desenvolvimento Psico - intelectual da Criança em Idade Escolar. In: LEONTIEV, A. et al. Psicologia e pedagogia: bases psicológicas da aprendizagem e do desenvolvimento. Tradução de Rubens Eduardo Frias. São Paulo: Centauro, 2005, p. 63-85.

BRASIL. Ministério de Educação e do Desporto. Secretaria de Educação Básica. Parâmetros Nacionais de Qualidade para a Educação Infantil. Brasília, DF: MEC, SEB, 2006, 2.v.

BRASIL. Ministério de Educação e do Desporto. Referencial Curricular Nacional para Educação Infantil. Brasília, DF: MEC, 1998, 3.v.

BRASIL. Lei de Diretrizes e Bases da Educação Nacional. Lei n. 9.394, de 20 de dezembro de 1996. Diário Oficial da União, Poder Executivo, Brasília, 23 dez. 1996.

CAMPOS, M. M. A educação infantil como direito. In: INSUMOS para o debate 2 - Emenda Constitucional n. ${ }^{\circ}$ 59/2009 e a educação infantil: impactos e perspectivas. São Paulo: Campanha Nacional pelo Direito à Educação, 2010, p. 8-14.

DAVIDOV, V. La enseñanza escolar y el desarrollo psíquico. Traducido del ruso por Marta Shuare. Moscou: Editorial Progresso, 1988.

ELKONIN, D. B. Desarrollo psíquico de los niños. In: SMIRNOV, A. A.; (Org.). Psicologia. Traducción por Florencio Villa Landa, 3. ed. México: Editorial Grijalbo, 1969, p. 493-560.

GOIÁS. Secretaria Municipal de Educação e Cultura. Ementário da Educação Infantil. Portaria $n^{\circ}$. 013/02 de 18/12/2002, CME.

GOIÁS. Secretaria Municipal de Educação e Cultura. Plano Municipal de Educação. Lei $n^{\circ} .2 .835$, de 26/05/2011.

GOIÁS. Secretaria Municipal de Educação e Cultura. Proposta Pedagógica Global da Rede Municipal de Ensino, nov. 2013.

INSUMOS para o debate 2 - Emenda Constitucional n. ${ }^{\circ}$ 59/2009 e a educação infantil: impactos e perspectivas. São Paulo: Campanha Nacional pelo Direito à Educação, 2010.

KOSTIUK, G. S. Alguns Aspectos da Relação Recíproca entre Educação e Desenvolvimento da Personalidade. In: LEONTIEV, A. et al. Psicologia e pedagogia: bases psicológicas da aprendizagem e do desenvolvimento. Tradução de Rubens Eduardo Frias. São Paulo: Centauro, 2005, p. 43-62. 
KRAMER, S. As crianças de 0 a 6 anos nas Políticas Educacionais no Brasil: Educação Infantil e/é Fundamental. Educ. Soc., Campinas, v. 27, n. 96, out., 2006, p. 797-818.

MANICA, A. P. Brincar/Jogo de Papéis Sociais e a Educação Infantil à luz da Psicologia Histórico-Cultural, 93s. Dissertação (Mestrado em Educação). Universidade Federal de Goiás, Unidade Acadêmica Especial de Educação, Programa de Pós-graduação em Educação, Catalão, 2018.

MARX, Karl. Prefácio da Segunda Edição. In: MARX, K. O capital: crítica da economia política. Tradução de Regis Barbosa e Flávio R. Kothe. São Paulo: Abril, 1983, p. 15-21 (Os Economistas).

MIEIB. Movimento Interfóruns de educação infantil do Brasil. Disponível em: https:// www.mieib.org.br/institucional/ Acesso em: 12 jul. 2020.

PASCHOAL, J. D.; MACHADO, M. C. G. A História da Educação Infantil no Brasil: avanços, retrocessos e desafios dessa modalidade educacional. Revista Histedbr On-line, Campinas, n. 33, mar. 2009, p. 78-95.

RODRIGUES, V. B. Políticas Públicas na Educação Brasileira: Caminhos Percorridos desde o Império até o Governo Lula. Sociais e Humanas, Santa Maria, v. 26, n. 1, jan./abr. 2013, p. 09-24.

SAVIANI, N. Educação infantil versus educação escolar implicações curriculares de uma (falsa) oposição. In: ARCE, A.; JACOMELI, M. R. M. (Orgs.). Educação infantil versus educação escolar? Entre a (des)escolarização e a precarização do trabalho pedagógico nas salas de aula. Campinas, SP: Autores Associados, 2012, p. 53-80.

SILVA, J. C. Projetos pedagógicos e os documentos oficiais do Ministério da Educação (MEC) o construtivismo e a pedagogia da infância como pano de fundo do processo de oposição ao ensino nas salas de aula de educação infantil. In: ARCE, A.; JACOMELI, M. R. M. (Orgs.). Educação infantil versus educação escolar? Entre a (des)escolarização e a precarização do trabalho pedagógico nas salas de aula. Campinas, SP: Autores Associados, 2012, p. 81-106.

VIGOTSKII, L. S. Aprendizagem e desenvolvimento intelectual na idade escolar. In: VIGOTSKII, L. S; LURIA, A. R.; LEONTIEV, A. N. Linguagem, desenvolvimento e aprendizagem. Tradução de Maria da Panha Villalobos. São Paulo: Ícone, 2006, p. 103-118.

VYGOTSKY, L. S. Aprendizagem e Desenvolvimento Intelectual na Idade Escolar. In: LEONTIEV, A. et al. Psicologia e pedagogia: bases psicológicas da aprendizagem e do desenvolvimento. Tradução de Rubens Eduardo Frias. São Paulo: Centauro, 2005, p. 25-42. 


\section{Dados das autoras}

\section{Elaine Lara Ferreira}

Graduada em Psicologia pela Universidade Federal de Catalão. Catalão/GO-Brasil. elainelarad@gmail.com

\section{Janaina Cassiano Silva}

Doutora em Educação pela Universidade Federal de São Carlos. São Carlos/SP-Brasil. Professora no Curso de Psicologia e no Programa de pós-graduação em Educação da Universidade Federal de Catalão. Catalão/GO-Brasil. janacassiano@ufg.br

Submetido em: 7-4-2020

Aceito em: 28-8-2020 